\title{
TAFA5 promotes proliferation and migration in gastric cancer
}

\author{
ZHIQING HU*, GENGMING NIU*, JUN REN*, XIN WANG, LIANG CHEN, RUNQI HONG and CHONGWEI KE \\ Department of General Surgery, The Fifth People's Hospital of Shanghai, Fudan University, Shanghai 200240, P.R. China
}

Received October 26, 2018; Accepted July 23, 2019

DOI: $10.3892 / \mathrm{mmr} .2019 .10724$

\begin{abstract}
TAFA chemokine like family member 5 (TAFA5), a TAFA family member that encodes small secreted proteins in the central nervous system, has been demonstrated to have increased expression in human malignancies. However, the expression and function of TAFA5 in gastric cancer (GC) remains unclear. In the present study, public datasets and human GC samples were used to determine the TAFA5 expression levels. The results revealed that TAFA5 was upregulated in GC when compared with adjacent normal tissues. Overexpression of TAFA5 in GC was associated with poor differentiation, and worse tumor, nodal and metastasis stages. In addition, high TAFA5 expression was correlated with unfavorable patient prognoses. In vitro experiments indicated that downregulation of TAFA5 inhibited the proliferation and migration of GC cell lines. Finally, the results from gene set enrichment analysis using data from The Cancer Genome Atlas revealed that TAFA5 expression was significantly correlated with genes associated with epithelial-mesenchymal transition, which was further confirmed by western blot analysis. In conclusion, the results of the present study suggested that TAFA5 had significant effects on GC progression, suggesting that it may serve as a potential therapeutic target for GC therapy.
\end{abstract}

\section{Introduction}

Gastric cancer (GC) is one of the most prevalent and lethal malignancies worldwide (1). Although its incidence and mortality rates have markedly declined in western countries over the last century $(2,3)$, GC remains a serious health burden in some parts of the world, such as China and Japan $(1,4)$. Surgery is currently the only available radical treatment for GC, but patients are often diagnosed at later stages, rendering them unfit for radical surgery, or they experience

Correspondence to: Dr Chongwei Ke, Department of General Surgery, The Fifth People's Hospital of Shanghai, Fudan University, 801 Heqing Road, Minhang, Shanghai 200240, P.R. China

E-mail: dr_kecw@163.com

*Contributed equally

Key words: TAFA chemokine like family member 5, gastric cancer, proliferation, migration, prognosis postsurgical disease relapse or metastasis, which worsens their prognosis (5). Comprehensive treatment for advanced GC remains unsatisfactory. Therefore, elucidation of the molecular mechanisms underlying GC invasion and metastasis is of vital importance.

TAFA chemokine like family member 5 (TAFA5), also known as Family with sequence similarity 19-member A5 C-C motif chemokine like, belongs to the TAFA family, which includes 5 members that are predominantly expressed in the central nervous system (6). These genes encode small secreted proteins named TAFA1-TAFA5, which are evolutionarily close to macrophage inflammatory protein 1A [currently known as chemokine C-C motif ligand 3 (CCL3)], a member of the small C-C chemokine family (6). Under physical conditions, TAFA5 colocalizes with vasopressin and oxytocin in the hypothalamic paraventricular nucleus, and may be involved in fluid homeostasis regulation (7). In addition, TAFA5 is a downstream target of Wnt family member 9 (Wnt9) b and can be activated by interactions between c-Myc and $\beta$-catenin to induce Wnt9b/ $\beta$-catenin-mediated progenitor renewal in the developing kidney $(8,9)$. Furthermore, TAFA5 inhibits osteoclast formation along with its receptor, formyl peptide receptor 2 (FPR2), by stimulating bone marrow-derived macrophages (10). Using a proteomic approach, Janvilisri et al (11) identified TAFA5 as one of the most increased serum tumor markers that could distinguish human cholangiocarcinoma from benign biliary tract diseases. In addition, Diaz de Stahl et al (12) analyzed 50 glioblastoma samples with a high-resolution tiling-path chromosome 22 array and discovered 2 amplified regions on chromosome 22 that were characteristics for patients with tumors. Further analysis of these regions revealed two novel genes, including TAFA5. As no such variation was identified in a series of normal individuals, the authors speculated that these genes were involved in glioma tumorigenesis (12). In a large-scale genome-wide association study, Wu et al (13) identified 5 loci associated with susceptibility to pancreatic cancer, including one that was located upstream of TAFA5 at chromosome 22.

Although an accumulating body of evidence has been suggestive of the involvement of TAFA5 in tumorigenesis, its role in GC development and progression remains unclear. The present study evaluated the clinical and prognostic significance of TAFA5 in 90 human GC samples and validated the results with data from two public datasets. The present study also investigated the in vitro activities of TAFA5 in cultured GC cells and characterized the potential underlying mechanisms of action. 


\section{Materials and methods}

Patients and specimens. A total of 18 paired human GC samples and their matched gastric normal tissues (NTs) were collected at the time of surgical resection at the Fifth People's Hospital of Shanghai, Fudan University (Shanghai, China) between February 2017 and February 2018. These samples were from 13 males and 5 females, with a median age of 64 (range 52-86). Patients were included in the study if they were initially diagnosed with GC, underwent the surgery and had complete clinicopathological information. Those who had extensively metastatic tumors, suffered from life-threatening diseases such as severe cardiovascular disease or had other types of tumors besides GC were excluded from the study. Samples were snap-frozen in liquid nitrogen and stored at $-80^{\circ} \mathrm{C}$. Paraffin-embedded tissues were retrieved from the Tissue Bank of the Fifth People's Hospital of Shanghai, Fudan University, and 4- $\mu \mathrm{m}$ tissue sections were prepared by the Department of Pathology of the same hospital. The present study was approved by the Institutional Ethics Committee at the Fifth People's Hospital of Shanghai, Fudan University (ethical approval form no. 2017-097) and adhered to the principles in the Declaration of Helsinki. Written informed consent was obtained from each patient prior to tissue collection for experimentation.

Tissue microarray and immunohistochemistry (IHC). Microarray sections of GCs and neighboring NTs were prepared by Shanghai Outdo Biotech Co., Ltd. These sections contained 90 paired GC and NTs from patients [the tissue microarray (TMA) cohort] and the clinicopathological characteristics of these patients are summarized in Table I. Following deparaffination, rehydration in graded ethanol, antigen retrieval with citrate buffer pH 6.0 (1:300 dilution; cat. no. ZLI-9065; OriGene Technologies, Inc.) and blocking with goat serum (1:20 dilution; cat. no. C0265; Beyotime Institute of Biotechnology) at room temperature for $1 \mathrm{~h}$, slides were stained with a rabbit polyclonal antibody against human TAFA5 (1:50 dilution; cat. no. 13948-1-AP; ProteinTech Group, Inc.) at $4^{\circ} \mathrm{C}$ overnight. Normal rat immunoglobulin $\mathrm{G}$ (1:50 dilution; cat. no. D110504; Sangon Biotech Co., Ltd.) instead of the primary antibody was used as a control. Subsequently, after washing with PBS, a horseradish peroxidase (HRP)-conjugated secondary antibody $(1: 2,000$; goat anti-rabbit, cat. no. A0208 and goat anti-rat, cat. no. A0192; Beyotime Institute of Biotechnology) was added and incubated at room temperature for $1 \mathrm{~h}$. Then, these sections were stained with 3,3'-diaminobenzidine (1:25 dilution; cat. no. GK500705; Gene Tech Co., Ltd.) at room temperature for $5 \mathrm{~min}$ and counterstained with 100\% hematoxylin (cat. no. C0107; Beyotime Institute of Biotechnology) at room temperature for 2 min. A modified $\mathrm{H}$-score system was used to semi-quantitate TAFA5 expression, as previously described (14). Briefly, the maximal intensity of staining ( 0 , negative; 1 , weak; 2 , moderate; and 3 , strong) was multiplied by the percentage of positive tumor cells $(0-100 \%)$ to generate the modified $\mathrm{H}$-score (range: 0-300). TAFA5 staining was categorized as high or low expression using the median $\mathrm{H}$-score.

Access to public datasets. The mRNA expression of TAFA5 in GC tissues and normal mucosae was acquired from Oncomine (www.oncomine.org) and Gene Expression Omnibus (GEO; accession no. GSE79973). The Cancer Genome Atlas (TCGA) Stomach Adenocarcinoma (STAD) RNA-sequence data and corresponding phenotype data were downloaded from UCSC Xena (https://xenabrowser.net/datapages/). The results in the present study are in whole or part based upon data generated by the TCGA Research Network (cancergenome.nih.gov). The expression of TAFA5 in TCGA STAD was further validated by two online analyzing tools specifically designed for TCGA data analysis (gepia.cancer-pku.cn/detail.php?gene=FAM19A5 and ualcan.path.uab.edu/cgi-bin/TCGAExResultNew2. pl?genenam=FAM19A5\&ctype=STAD). The original data for the prognostic analysis of TAFA5 were downloaded from Kaplan-Meier Plotter (www.kmplot.com) and UCSC Xena (xenabrowser.net/heatmap/).

Cell lines. A gastric epithelial cell line (GES-1) and GC cell lines (AGS, HGC27, NCI-N87, MGC803 and SNU-1) were obtained from the Type Culture Collection of the Chinese Academy of Sciences. All of the cells were validated by short tandem repeat DNA profiling and were confirmed negative for Mycoplasma contamination. Cells were cultured in RPMI-1640 (BBI Life Sciences Corporation) or F12K medium (Zhong Qiao Xin Zhou Biotechnology Co., Ltd.) supplemented with $10 \%$ fetal bovine serum (cat. no. E600001; Sangon Biotech Co., Ltd.), $100 \mu \mathrm{g} / \mathrm{ml}$ penicillin, and $100 \mathrm{mg} / \mathrm{ml}$ streptomycin at $37^{\circ} \mathrm{C}$ with $5 \% \mathrm{CO}_{2}$ in a humidified incubator (Thermo Fisher Scientific, Inc.).

Construction of TAFA5-targeting short hairpin (sh)-RNAs and packaging of lentiviruses. Two targeting shRNAs (shTAFA5-1 and shTAFA5-2) and a nontargeting scrambled RNA (scramble) were subcloned into the GV248 lentivirus vector by Shanghai GeneChem Co., Ltd. The shTAFA5-1 target sequence was 5'-CGCAAGAATCATCAAGACCAA-3', and the shTAFA5-2 target sequence was 5'-CACCTGTGA GATTGTGACCTT-3'. Lentiviral stocks were prepared, as previously described (15).

$R N A$ extraction and reverse transcription-quantitative PCR $(R T-q P C R)$. Total RNA was isolated from cell cultures or from snap-frozen tissues from patients with GC using RNAiso Plus (Takara Bio, Inc.), according to the manufacturer's instructions, and reverse transcribed with HiScript Q Select RT SuperMix (cat. no. R132-01; Vazyme Biotech Co., Ltd.), according to the manufacturer's protocol. qPCR was performed with SYBR Green Master Mix (cat. no. Q131-02; Vazyme Biotech Co., Ltd.) and quantified using the $2^{-\Delta \Delta \mathrm{Cq}}$ method (16). The thermocycling conditions were as follows: $95^{\circ} \mathrm{C}$ for $30 \mathrm{sec}$, followed by 40 cycles of $95^{\circ} \mathrm{C}$ for $10 \mathrm{sec}, 60^{\circ} \mathrm{C}$ for $32 \mathrm{sec}, 95^{\circ} \mathrm{C}$ for $15 \mathrm{sec}, 60^{\circ} \mathrm{C}$ for $60 \mathrm{sec}$ and $95^{\circ} \mathrm{C}$ for $15 \mathrm{sec}$. Each sample was assayed in duplicate. All PCR products were confirmed by $2.0 \%$ agarose gel electrophoresis. The sequences of the primers were as follows: TAFA5, forward 5'-GTGAGTTTG GCCACTCCGTA-3' and reverse 5'-GAATGGACAGATGGC TGGCA-3'; and GAPDH, forward 5'-GTCAAGGCTGAG AACGGGAA-3' and reverse 5'-AAATGAGCCCCAGCCTTC TC-3'. Experiments were repeated three times in duplicate.

Western blotting. Total protein was extracted from cell cultures or homogenized tissues from patients with GC 
Table I. Clinical and pathologic features of patients with gastric cancer ${ }^{\mathrm{a}}(\mathrm{n}=90)$.

\section{Feature}

Number of patients (\%)

\section{Sex}

Male

69 (76.7)

Female

$21(23.3)$

Age

$<70$

$\geq 70$

G2

28 (31.1)

G3

Tumor size $(\mathrm{cm})$

$<5$

$35(38.9)$

$\geq 5$

$54(60.0)$

NA

1 (1.1)

TNM stage

I

II

III

IV

12 (13.3)

$27(30.0)$

49 (54.5)

2 (2.2)

Tumor stage

T1

T2

15 (16.7)

46 (51.1)

24 (26.6)

T4

24 (26.7)

15 (16.7)

23 (25.5)

28 (31.1)

N3

Yes

1 (1.1)

NA

49 (54.4)
Differentiation

standard methods as previously described (17). Briefly, proteins $(30 \mu \mathrm{g})$ were separated by $10 \%$ SDS-PAGE and then transferred onto a polyvinylidene fluoride membrane. Subsequently, the membranes were blocked with $5 \%$ fat-free dry milk at room temperature for $1 \mathrm{~h}$. Then, the blots were incubated with a rabbit polyclonal antibody against TAFA5 (1:1,000 dilution; cat. no. 13948-1-AP; ProteinTech Group, Inc.) and monoclonal antibodies against E-cadherin, $\mathrm{N}$-cadherin, Vimentin and ZEB-1 (1:1,000 dilution; cat. nos. 3195, 13116, 5741 and 3396, respectively; Cell Signaling Technology, Inc.) overnight at $4^{\circ} \mathrm{C}$. GAPDH (1:2,000; rabbit anti-human; cat. no. AF1186; Beyotime Institute of Biotechnology) or $\beta$-actin $(1: 2,000$; mouse anti-human; cat. no. AF0003; Beyotime Institute of Biotechnology) were detected as the loading controls. The membranes were washed with TBST and incubated with the respective HRP-conjugated secondary antibodies (1:2,000; goat anti-mouse cat. no. A0216 and goat anti-rabbit cat. no. A0208; Beyotime Institute of Biotechnology) at room temperature for $1 \mathrm{~h}$. The proteins were finally visualized using an enhanced chemiluminescence system (cat. no. P0018AS; Beyotime Institute of Biotechnology). The grayscale values of protein bands were analyzed using ImageJ software (National Institutes of Health).

Proliferation assay. Stably infected AGS and HGC-27 cells $\left(2 \times 10^{3}\right.$ cells/well) were seeded in 96 -well plates and cultured for 24, 48, 72 or 96 h. Then, $10 \mu \mathrm{l}$ Cell Counting Kit-8 (CCK-8) reagent (10\% v/v in serum-free RPMI-1640 medium; Beyotime Institute of Biotechnology) was added to each well and incubated at $37^{\circ} \mathrm{C}$ for $1 \mathrm{~h}$. Absorbance was measured at $450 \mathrm{~nm}$ using a microplate reader (BioTek Synergy 2; BioTek Instruments, Inc.).

Migration assay. A Transwell migration assay was performed as previously reported (18). Briefly, cells $\left(4 \times 10^{5}\right.$ cells $\left./ \mathrm{ml}\right)$ were seeded in serum-free RPMI-1640 or F12K medium in the top chamber of the Transwell insert. Medium containing $20 \%$ FBS in the lower chamber served as chemoattractant. Following incubation for $24 \mathrm{~h}$ at $37^{\circ} \mathrm{C}$, the cells on the top side of the membrane were removed with a cotton swab, and the migrated cells on the bottom side were fixed with methanol for $20 \mathrm{~min}$ and then stained with crystal violet (0.1\% in PBS) for $15 \mathrm{~min}$. A total of 6 randomly selected fields per well were imaged under an inverted microscope (Leica Microsystems $\mathrm{GmbH}$ ) using the ImageScope software (Leica Microsystems $\mathrm{GmbH}$ ) with a magnification of x 200 . Then cells were manually counted and analyzed by Excel 2010 (Microsoft Corporation) and the number of migrated cells was counted.

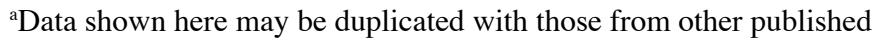
resources that are based on the same commercial tissue microarray cohort. NA, information not available.

using radioimmunoprecipitation assay lysis buffer (Beyotime Institute of Biotechnology) containing phenylmethylsulfonyl fluoride (Beyotime Institute of Biotechnology) and proteinase inhibitor cocktail solution (Roche Diagnostics), and quantified via the bicinchoninic acid assay method, as recommended by the manufacturer. Western blotting was performed according to
Scratch wound healing assay. A monolayer scratch wound assay was employed to evaluate cell migration, as previously

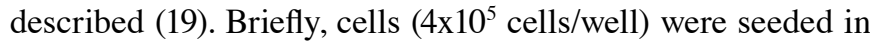
12 -well plates and grown to nearly $100 \%$ confluence in $10 \%$ FBS-containing medium, before being washed with PBS and transferred to serum-free medium for $24 \mathrm{~h}$. Then, a scratch wound was generated with a $200 \mu 1$ pipette tip. Wound closure was imaged at 0, 24 and $48 \mathrm{~h}$ under an inverted microscope (Leica Microsystems $\mathrm{GmbH}$ ) using the ImageScope software (Leica Biosystems $\mathrm{GmbH}$ ) with a magnification of $\mathrm{x} 40$. Then 
A

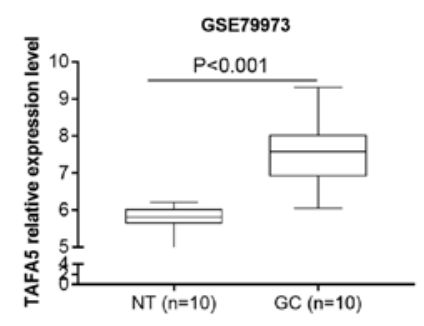

D

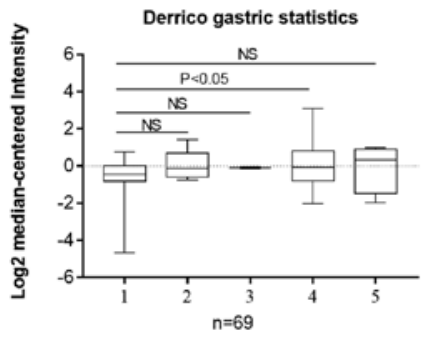

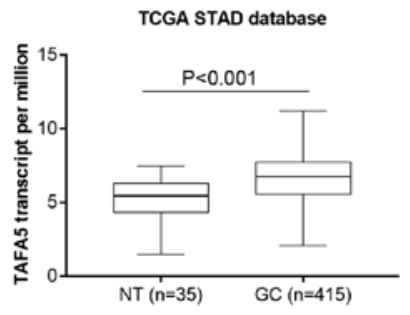

E

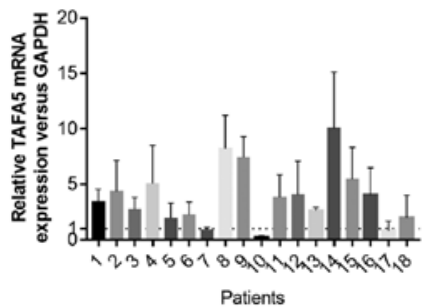

G

\begin{tabular}{|c|c|c|c|c|c|c|}
\hline \multirow[t]{2}{*}{ Patients } & 1 & 2 & 3 & 4 & 5 & 6 \\
\hline & NT GC & NT GC & NT GC & NT GC & NT GC & NT GC \\
\hline \multirow{2}{*}{$\begin{array}{r}\text { TAFA5 } \\
\text { GAPDH }\end{array}$} & $\approx$ & $=-$ & -2 & $=$ & $=-\infty$ & $=-$ \\
\hline & $-\infty$ & $-\infty$ & $-\infty$ & $-\infty$ & $-\infty$ & -5 \\
\hline \multirow[t]{2}{*}{ Patients } & 7 & 8 & 9 & 10 & 11 & 12 \\
\hline & NT GC & NT GC & NT GC & NT GC & NT GC & NT GC \\
\hline \multirow{2}{*}{$\begin{array}{l}\text { TAFA5 } \\
\text { GAPDH }\end{array}$} & $-\cdots$ & - & -0 & -- & $=$ & -1 \\
\hline & 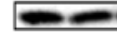 & 60 & $\bar{x}$ & & & 20 \\
\hline \multirow[t]{2}{*}{ Patients } & 13 & 14 & 15 & 16 & 17 & 18 \\
\hline & NT GC & NT GC & NT GC & NT GC I & NT GC I & NT GC \\
\hline TAFA5 & E- & $\approx$ & $=$ & $\cdots$ & $=\cdots$ & $\Rightarrow$ \\
\hline
\end{tabular}

C

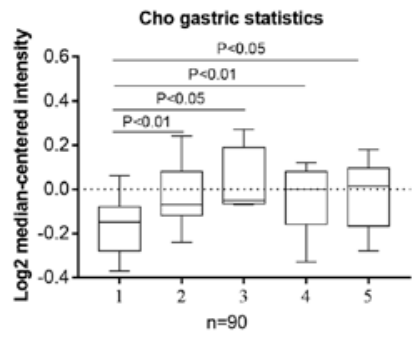

$\mathrm{F}$

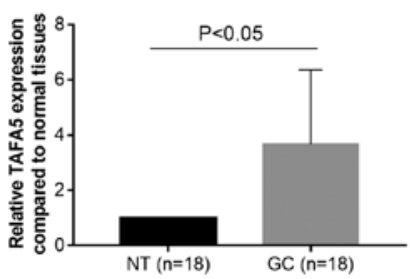

H

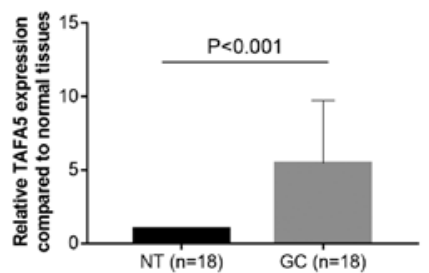

Figure 1. TAFA5 is upregulated in GC. (A) TAFA5 expression was upregulated in GC tissues compared with NTs (n=10 per group) in the GSE79973 database. (B) TAFA5 expression was upregulated in GC $(n=415)$ when compared with NTs $(n=35)$ in TCGA cohort. (C) A logarithmic $2^{-\Delta \Delta C q}$ scale was used to represent the fold-changes in TAFA5 mRNA expression in the microarray datasets from the Oncomine Cho gastric and (D) Derrico gastric databases. The cases were grouped as follows: 1, no value; 2, gastric intestinal type adenocarcinoma; 3, gastric mixed adenocarcinoma; 4, diffuse gastric adenocarcinoma; and 5, gastric adenocarcinoma. (E and F) TAFA5 mRNA expression levels in 18 paired GC tissues and their adjacent NTs. (G and H) Representative blots and quantification of TAFA5 protein expression levels from the 18 paired GC tissues and their adjacent NTs. The average TAFA5 expression was normalized to the expression of GAPDH. A total of 3 replicates were conducted for each experiment. TAFA5, TAFA chemokine like family member 5; GC, gastric cancer; NT, normal tissue; TCGA, The Cancer Genome Atlas; NS, not significant.

the wound closure rates were analyzed by ImageJ (v1.8.0; National Institutes of Health).

Gene set enrichment analysis. The Gene set enrichment analysis (GSEA) is developed by the Broad Institute website (http://www.broadinstitute.org/gsea/index.jsp). All GSEA analyses were performed using the GSEA 2.2.2 software. The TCGA STAD RNA-seq data were loaded into GSEA and run with the latest version of Hallmarks gene sets. The number of permutations was set at 1,000 , and patient data were divided into TAFA5 high and low groups by the median of TAFA5 expression. Then GESA was performed according to the default weighted enrichment statistics and genes were ranked by the Pearson method. Gene sets were considered significantly enriched if $\mathrm{P}<0.05$ and FDR $<0.25$. Those gene sets that were significantly enriched in the TAFA5 high group were designated as TAFA5-positively related gene sets, while those that were significantly enriched in the TAFA5 low group were designated as TAFA5-negatively correlated gene sets.

Statistical analysis. Analyses were performed using Microsoft Excel 2010 (Microsoft Corporation), GraphPad Prism7 (GraphPad Software, Inc.), and SPSS version 22 (IBM Corp.). Student's t-test was used for statistical comparisons between two groups, while statistical comparisons among multiple groups were performed by one-way analysis of variance followed by Bonferroni's post hoc test. Pearson's $\chi^{2}$ test and Fisher's exact test were used for categorical comparisons. Survival analyses were conducted using the Kaplan-Meier method. Univariate and multivariate survival analyses were 
A $\mathbf{a}$

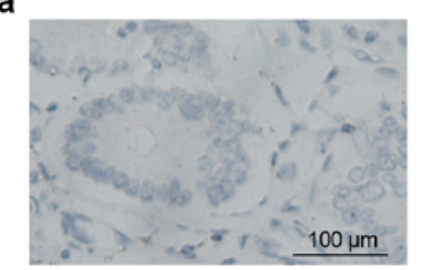

b

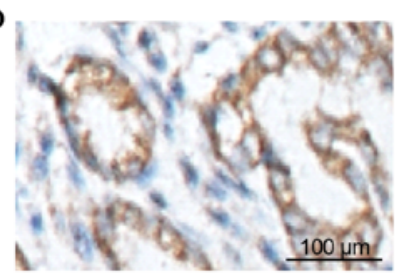

B

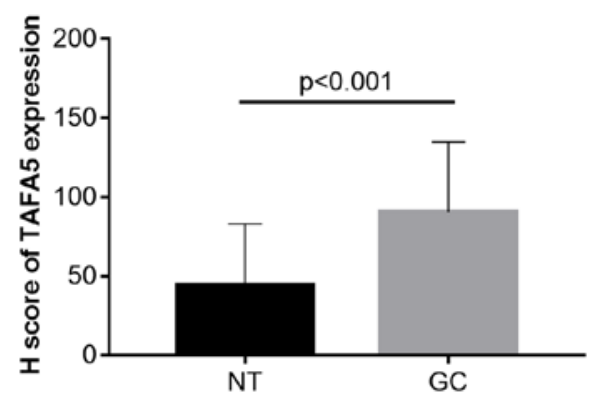

D

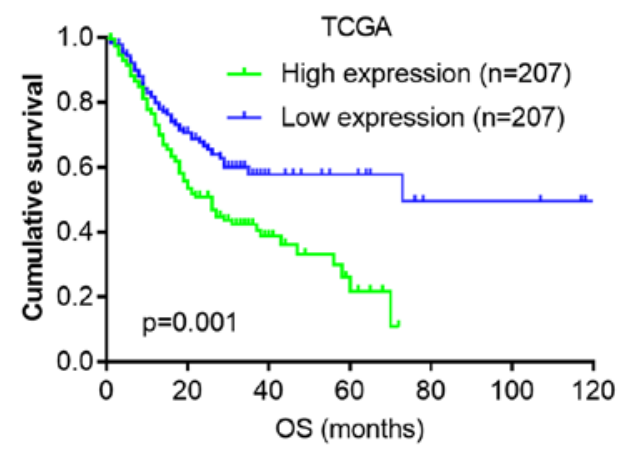

$\mathbf{F}$

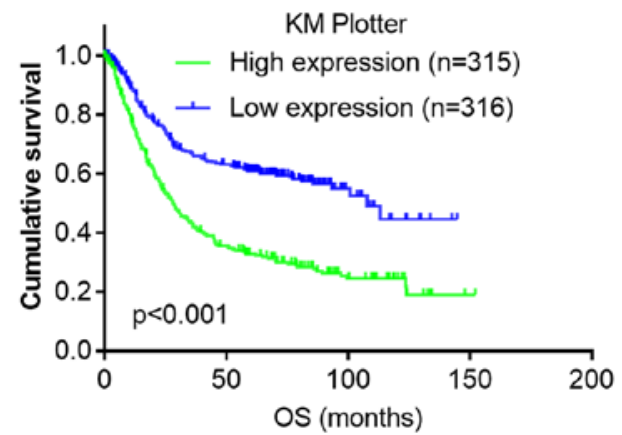

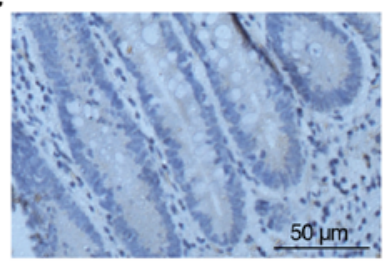

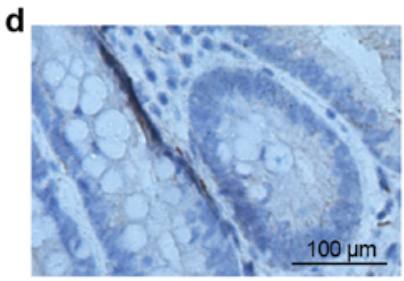

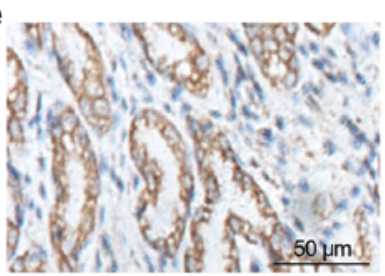

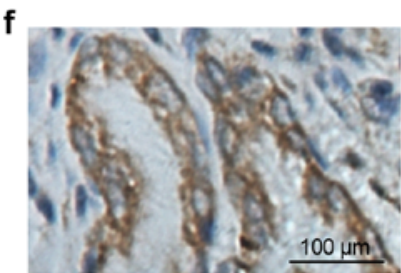

C

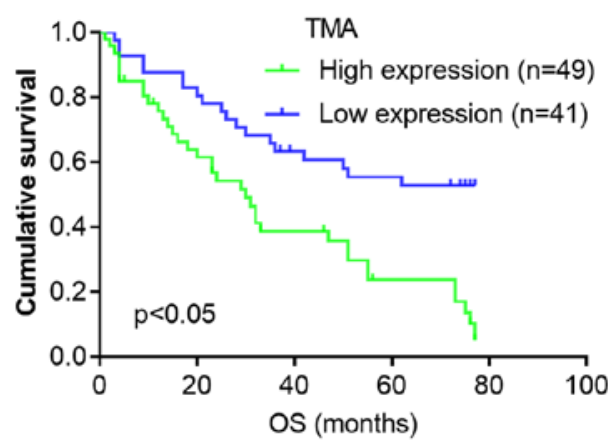

E TCGA

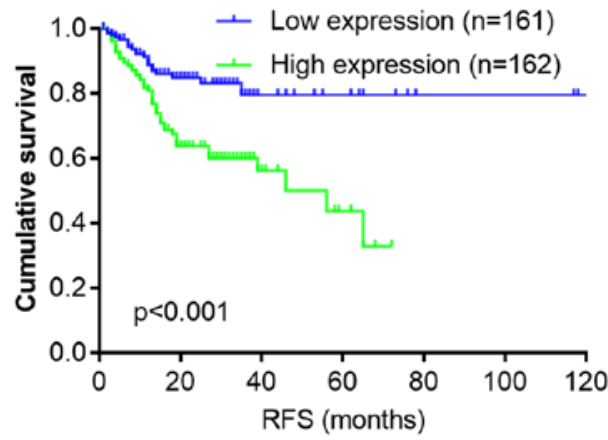

G

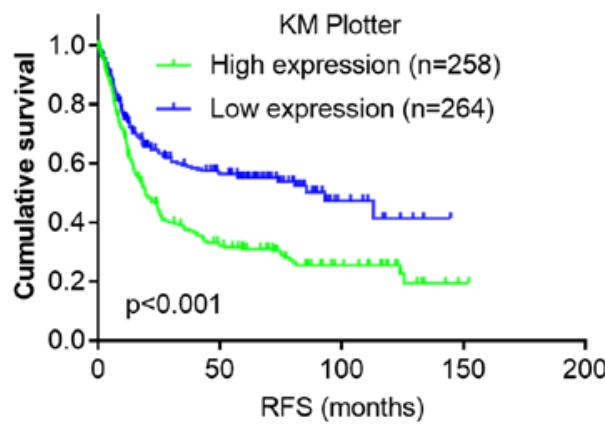

Figure 2. TAFA5 overexpression in GC is associated with poor patient survival. (A) Immunohistochemical staining of TAFA5 in GC tissues and NTs. (A-a) Immunoglobulin G negative control. (A-b) Positive staining of TAFA5 in GC tissue (magnification, $\mathrm{x} 400$ ). (A-c) TAFA5 staining in NT (magnification, x200), (A-d) TAFA5 staining in NT (magnification, x400). (A-e) TAFA5 staining in GC tissue (magnification, x200). (A-f) TAFA5 staining in GC tissue (magnification, $\mathrm{x}$ 400). (B) H-scores of TAFA5 staining in NTs and GC. (C) Kaplan-Meier plots for the OS of patients in the TMA cohort. (D) Kaplan-Meier plots for OS and (E) RFS in TCGA cohort. (F) Kaplan-Meier plots for OS and (G) RFS in the Kaplan-Meier Plotter cohort. P-values were obtained using the log-rank test. Censored data are indicated by the + symbol. Patients were stratified into low and high TAFA5 expression groups according to TAFA5 mRNA expressions (<median vs. $\geq$ median) in the TCGA and Kaplan-Meier Plotter cohorts, or H-scores of TAFA5 staining (<median vs. $\geq$ median) in the TMA cohort. TAFA5, TAFA chemokine like family member 5; GC, gastric cancer; NT, adjacent normal tissue; OS, overall survival; RFS, recurrence-free survival; TCGA, The Cancer Genome Atlas; TMA, tissue microarray. 
Table II. Association between TAFA5 expression and clinicopathological variables in gastric cancer $(n=90)$.

\begin{tabular}{|c|c|c|c|c|}
\hline \multirow[b]{2}{*}{ Clinicopathological feature } & \multirow[b]{2}{*}{ Number of patients } & \multicolumn{3}{|c|}{ TAFA5 expression } \\
\hline & & Low (41) & High (49) & P-value \\
\hline \multicolumn{5}{|l|}{ Sex } \\
\hline Male & 69 & $32(46.4)$ & $37(53.6)$ & \\
\hline Female & 21 & $9(42.9)$ & $12(57.1)$ & 0.488 \\
\hline \multicolumn{5}{|l|}{ Age } \\
\hline$<70$ & 45 & $22(48.9)$ & $23(51.1)$ & \\
\hline$\geq 70$ & 45 & $19(42.2)$ & $26(57.8)$ & 0.336 \\
\hline \multicolumn{5}{|l|}{ Histological grade } \\
\hline G2 & 28 & $18(64.3)$ & $10(35.7)$ & \\
\hline G3 & 62 & $23(37.1)$ & $39(62.9)$ & 0.015 \\
\hline \multicolumn{5}{|l|}{ Tumor size $(\mathrm{cm})$} \\
\hline$<5$ & 35 & $18(51.4)$ & $17(48.6)$ & \\
\hline$\geq 5$ & 54 & $22(40.7)$ & $32(59.3)$ & 0.220 \\
\hline \multicolumn{5}{|l|}{ Tumor stage } \\
\hline $\mathrm{T} 1 / \mathrm{T} 2$ & 20 & $17(85.0)$ & $3(15.0)$ & \\
\hline $\mathrm{T} 3 / \mathrm{T} 4$ & 70 & $24(34.3)$ & $46(65.7)$ & 0.001 \\
\hline \multicolumn{5}{|l|}{ Nodal stage } \\
\hline No & 24 & $16(66.7)$ & $8(33.3)$ & \\
\hline N1-N3 & 66 & $25(37.9)$ & $41(62.1)$ & 0.014 \\
\hline \multicolumn{5}{|l|}{ TNM stage } \\
\hline $\mathrm{I} / \mathrm{II}$ & 38 & $24(63.2)$ & $14(36.8)$ & \\
\hline III/IV & 52 & $17(32.7)$ & $35(67.3)$ & 0.004 \\
\hline \multicolumn{5}{|l|}{ Vessel invasion } \\
\hline No & 74 & $34(45.9)$ & $40(54.1)$ & \\
\hline Yes & 16 & $7(43.8)$ & $9(56.2)$ & 0.548 \\
\hline \multicolumn{5}{|l|}{ Nerve invasion } \\
\hline No & 74 & $35(47.3)$ & $39(52.7)$ & \\
\hline Yes & 15 & $6(40.0)$ & $9(60.0)$ & 0.410 \\
\hline
\end{tabular}

conducted with the Cox proportional hazards regression model. All statistical tests were two-sided. $\mathrm{P}<0.05$ was considered to indicate a statistically significant difference.

\section{Results}

TAFA5 is upregulated in GC. By analyzing the TAFA5 expression profile data from a GEO GC dataset (GSE79973), the present study revealed that TAFA5 was upregulated in GC tissues compared with NTs ( $n=10$ pairs; $P<0.001$; Fig. 1A). RNA sequencing data from TCGA STAD also revealed an increase in TAFA5 expression in GC tissues $(n=415)$ compared with in NTs $(n=35 ; P<0.001$; Fig. 1B), which was further validated by online analysis tools Gepia and Ualcan (data not shown). Two additional GC datasets [Derrico gastric(GEO: GSE13911), n=69; and Cho gastric(GEO: GSE13861), n=90] $(20,21)$ with Lauren's classification in the Oncomine database indicated that TAFA5 was generally overexpressed in each cancer group when compared with the control group, although the differences were not significant in three cases with smaller samples (Fig. 1C and D). To further validate these observations, the present study measured TAFA5 expression in 18 GC tissues and their matched NTs by RT-qPCR and western blotting. The results indicated that TAFA5 mRNA and protein expression levels were increased in GC tissues compared with NTs (Fig. 1E-H). Taken together, these results indicated that TAFA5 was upregulated in GC.

Overexpression of TAFA5 in GC correlates with unfavorable prognosis. To test the hypothesis that TAFA5 protein abundance in GC contributes to increased malignancy, the present study examined the TAFA5 expression levels in primary GC tissues of a TMA cohort by IHC. As shown in Fig. 2A, TAFA5 was mainly expressed in the cytoplasm of cancer cells, and its expression was stronger in GC tissues than in NTs. The $\mathrm{H}$-score was then used to quantitate TAFA5 staining in these tissues, which revealed that TAFA5 expression was significantly increased in GC compared with NTs (Fig. 2B). The associations between TAFA5 expression and clinicopathological variables are summarized in Table II. High TAFA5 
A
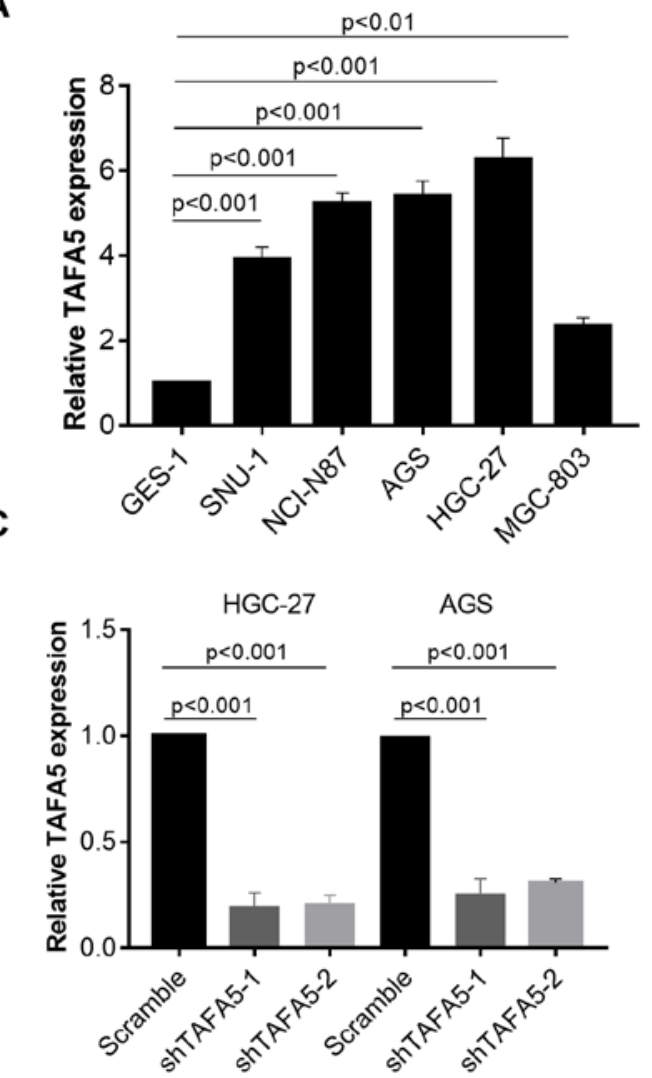

B
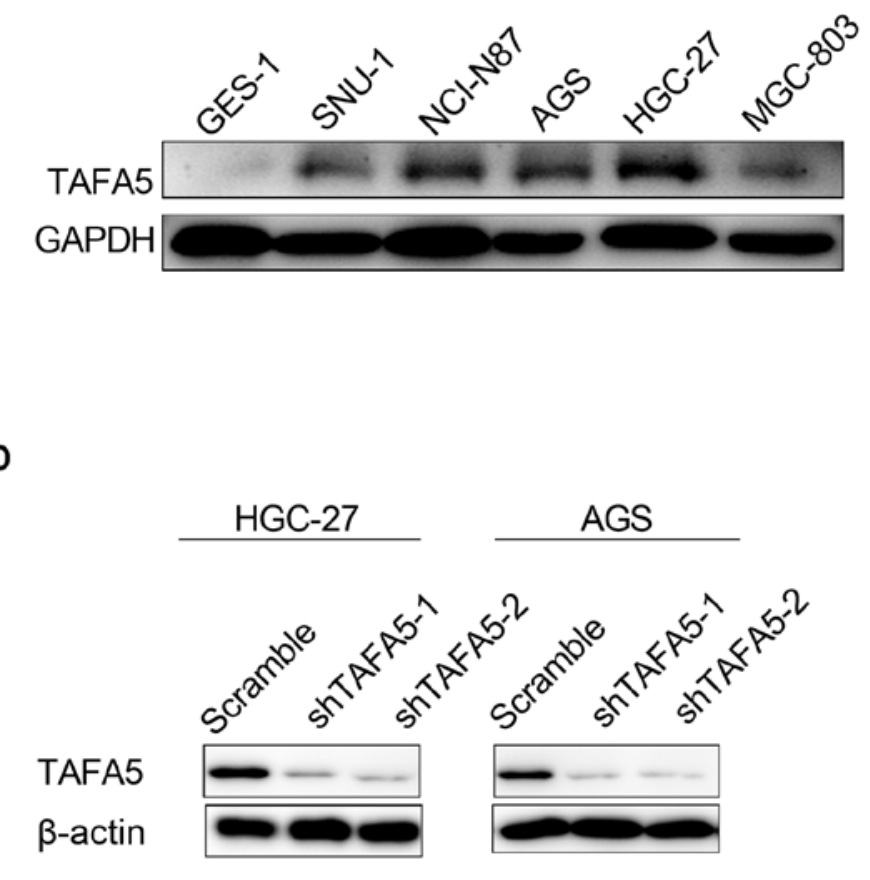

Figure 3. Silencing of TAFA5 in GC cells. (A) TAFA5 mRNA and (B) TAFA5 protein expression levels in a normal gastric mucosa cell line (GES-1) and in five GC cell lines. (C and D) HGC-27 and AGS cells were infected with lentiviruses carrying shTAFA5-1, shTAFA5-2 or scrambled control shRNA, then underwent validation by reverse transcription-quantitative PCR and western blot analysis. TAFA5, TAFA chemokine like family member 5; sh, short hairpin RNA; GC, gastric cancer.

expression was significantly associated with poor differentiation, and worse tumor, nodal and metastasis stages.

Next, the present study determined the association between TAFA5 expression and patient outcomes. Kaplan-Meier survival analysis of the TMA cohort revealed that patients with high TAFA5 expression exhibited a shorter overall survival (OS) compared with those with low expression [estimated mean OS 30.5 months with $95 \%$ confidence interval (CI) 22.9-38.1 months vs. OS 53.0 months with $95 \%$ CI 44.5-61.6 months; log-rank test, $\mathrm{P}=0.001$; Fig. $2 \mathrm{C}$ ]. To further confirm the adverse prognostic role of TAFA5 in patients with GC, the present study downloaded and analyzed TAFA5 transcription data from TCGA and Kaplan-Meier Plotter datasets. The results demonstrated that high TAFA5 expression was correlated with worse OS and recurrence-free survival (RFS) in both patient cohorts (Fig. 2D-G). Multivariate analysis using a Cox proportional hazards model revealed that TAFA5 overexpression was significantly associated with shorter OS [hazard ratio (HR), 1.90; 95\% CI, 1.04-3.44; $\mathrm{P}=0.036$ ], following adjustments for tumor size, tumor stage and nodal stage (Table III). Taken together, these results indicated that TAFA5 was a prognostic marker in GC that was associated with unfavorable prognoses.

TAFA5 promotes the proliferation and migration of cultured GC cells. To gain insight into the potential role of TAFA5 in GC progression, the present study first examined the intrinsic expression levels of TAFA5 in a normal gastric epithelial cell line, GES-1, and in five GC cell lines, via RT-qPCR and western blotting. The results indicated that TAFA5 expression was markedly increased in GC cells when compared with GES-1 cells (Fig. 3A and B). TAFA5 expression was then silenced in HGC-27 and AGS cells with lentiviruses carrying two TAFA5-specific shRNAs (Fig. 3C and D). In cultured GC cells, CCK-8 assays revealed that knockdown of TAFA5 expression significantly inhibited proliferation (Fig. 4A and B). In addition, knockdown of TAFA5 expression decreased cell migration in the scratch wound healing assay (Fig. 4C and D) and in the Transwell migration assay (Fig. 4E and F). Collectively, these results indicated that TAFA5 promoted the proliferation and migration of GC cells.

TAFA5 may function by modulating epithelial-mesenchymal transition (EMT) in GC. To characterize the potential mechanism of TAFA5 in promoting tumor progression, the present study used the RNA-seq data for GC samples from TCGA to conduct gene set enrichment analysis (GSEA) $(22,23)$. The results revealed that TAFA5 expression was positively correlated with genes involved in EMT, but not with those in the Wnt/ $\beta$-catenin signaling pathway (Fig. 5A). Furthermore, as shown in Fig. 5B, TAFA5 expression was moderately positively correlated with snail family transcriptional repressor (SNAI) 1, SNAI2, twist family bHLH transcription factor (TWIST) 1, TWIST2, zinc finger E-box binding homeobox (ZEB) 1, ZEB2, Vimentin, $\mathrm{N}$-cadherin, Wnt9a and Wnt9b, and weakly correlated with 
Table III. Univariate and multivariate Cox proportional hazard models for overall survival in patients with gastric cancer ( $\mathrm{n}=90$ )

\begin{tabular}{|c|c|c|c|c|}
\hline \multirow[b]{2}{*}{ Clinicopathological features } & \multicolumn{2}{|c|}{ Univariate analysis } & \multicolumn{2}{|c|}{ Multivariate analysis } \\
\hline & $\mathrm{HR}(95 \% \mathrm{CI})$ & P-value & $\mathrm{HR}(95 \% \mathrm{CI})$ & P-value \\
\hline \multicolumn{5}{|l|}{ Sex } \\
\hline Male & 1 (Reference) & & & \\
\hline Female & $0.60(0.30-1.18)$ & 0.137 & & \\
\hline \multicolumn{5}{|l|}{ Age } \\
\hline$<70$ & 1 (Reference) & & & \\
\hline$\geq 70$ & $1.67(0.99-2.82)$ & 0.055 & & \\
\hline \multicolumn{5}{|l|}{ Histological grade } \\
\hline $\mathrm{G} 2$ & 1 (Reference) & & & \\
\hline G3 & $1.51(0.85-2.69)$ & 0.162 & & \\
\hline \multicolumn{5}{|l|}{ Tumor size (cm) } \\
\hline$<5$ & 1 (Reference) & & 1 (Reference) & \\
\hline$\geq 5$ & $3.38(1.83-6.22)$ & 0.001 & $2.48(1.28-4.77)$ & 0.007 \\
\hline \multicolumn{5}{|l|}{ Tumor stage } \\
\hline $\mathrm{T} 1 / \mathrm{T} 2$ & 1 (Reference) & & 1 (Reference) & \\
\hline $\mathrm{T} 3 / \mathrm{T} 4$ & $4.08(1.75-9.56)$ & 0.001 & $1.61(0.62-4.22)$ & 0.330 \\
\hline \multicolumn{5}{|l|}{ Nodal stage } \\
\hline No & 1 (Reference) & & 1 (Reference) & \\
\hline N1-N3 & $3.27(1.55-6.93)$ & 0.002 & $1.94(0.88-4.29)$ & 0.100 \\
\hline \multicolumn{5}{|l|}{ TNM stage } \\
\hline $\mathrm{I} / \mathrm{II}$ & 1 (Reference) & & & \\
\hline III/IV & $3.46(1.90-6.29)$ & 0.001 & & \\
\hline \multicolumn{5}{|l|}{ Vessel invasion } \\
\hline No & 1 (Reference) & & & \\
\hline Yes & $1.05(0.53-2.08)$ & 0.888 & & \\
\hline \multicolumn{5}{|l|}{ Nerve invasion } \\
\hline No & 1 (Reference) & & & \\
\hline Yes & $1.02(0.50-2.07)$ & 0.963 & & \\
\hline \multicolumn{5}{|l|}{ TAFA5 expression } \\
\hline Low & 1 (Reference) & & 1 (Reference) & \\
\hline High & $2.63(1.51-4.58)$ & 0.001 & $1.90(1.04-3.44)$ & 0.036 \\
\hline
\end{tabular}

SNAI3, E-cadherin and $\beta$-catenin (data not shown). In addition, protein expression levels of the epithelial marker E-cadherin were increased, while the mesenchymal markers N-cadherin and Vimentin, and the EMT-associated transcription factor ZEB1 were decreased, following TAFA5 silencing in GC cells (Fig. 5C). Taken together, these results suggested an active role for TAFA5 in promoting tumor aggressiveness via EMT in GC.

\section{Discussion}

Due to effective early screening and Helicobacter pylori eradication, great achievements have been made in controlling the prevalence and mortality rates of GC (1). However, GC remains a serious health threat in some parts of the world, such as China, due to early metastasis and postsurgical relapse $(4,5)$.
Comprehensive therapy is often ineffective in patients at later stages; thus, a better understanding of the mechanisms underlying disease progression, and identification of potential therapeutic targets, would be clinically and scientifically beneficial. In the present study, TAFA5 was upregulated in GC tissues and cell lines. High expression of TAFA5 was significantly associated with worse clinical characteristics and unfavorable prognosis in patients with GC. The prognostic value of TAFA5 was validated using data from TCGA and Kaplan-Meier Plotter databases. Knockdown of TAFA5 expression inhibited the proliferation and migration of cultured GC cells. Taken together, the present results indicated that TAFA5 may be a novel prognostic marker in patients with GC and that it may have a crucial role in promoting tumor progression via the regulation of cell proliferation and migration. 
A

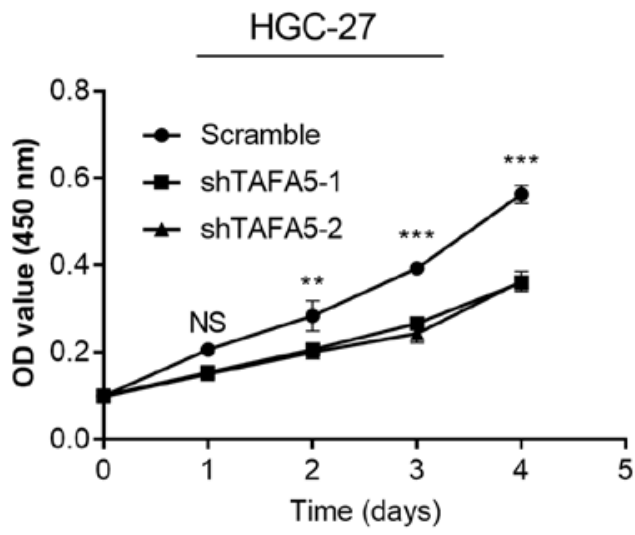

C

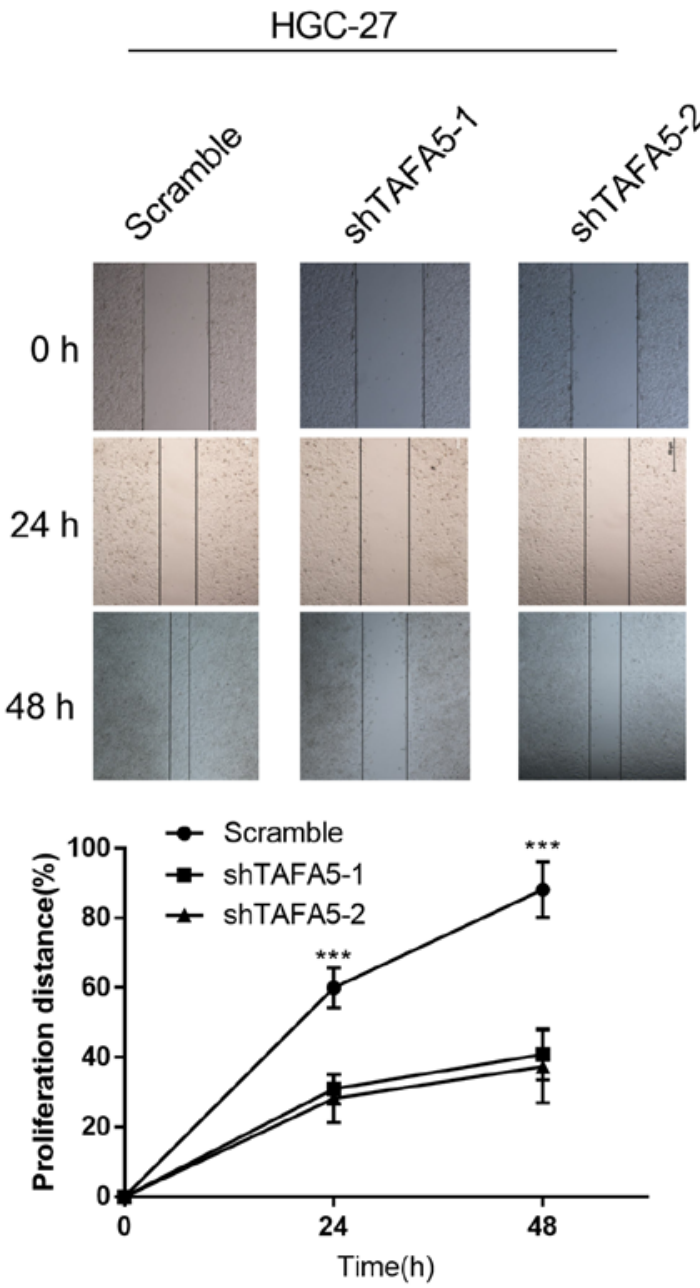

$\mathrm{E}$

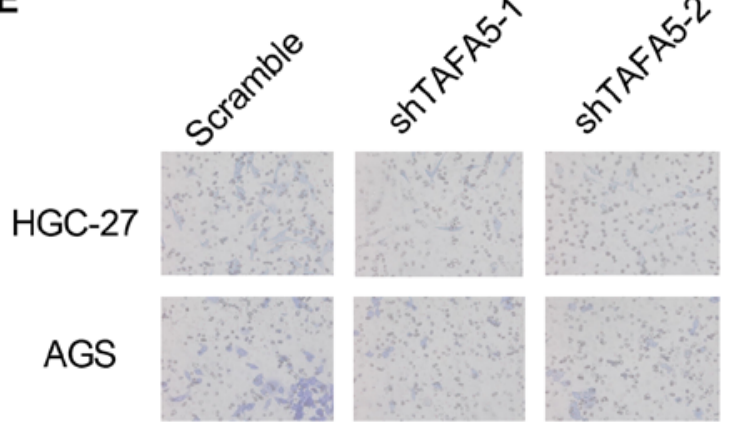

B

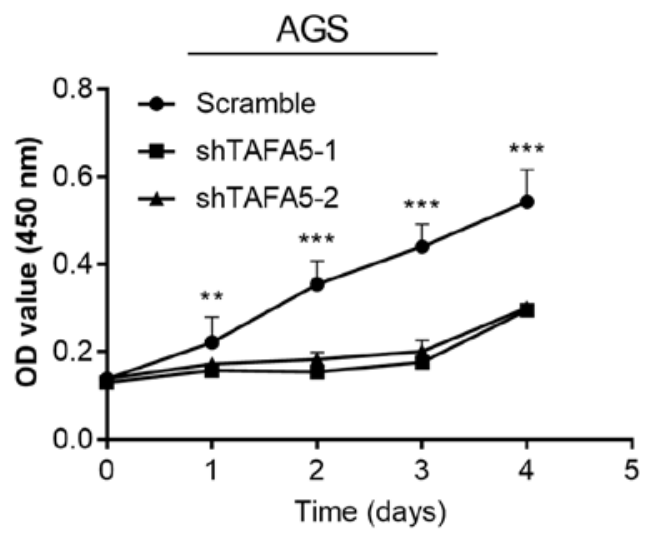

D
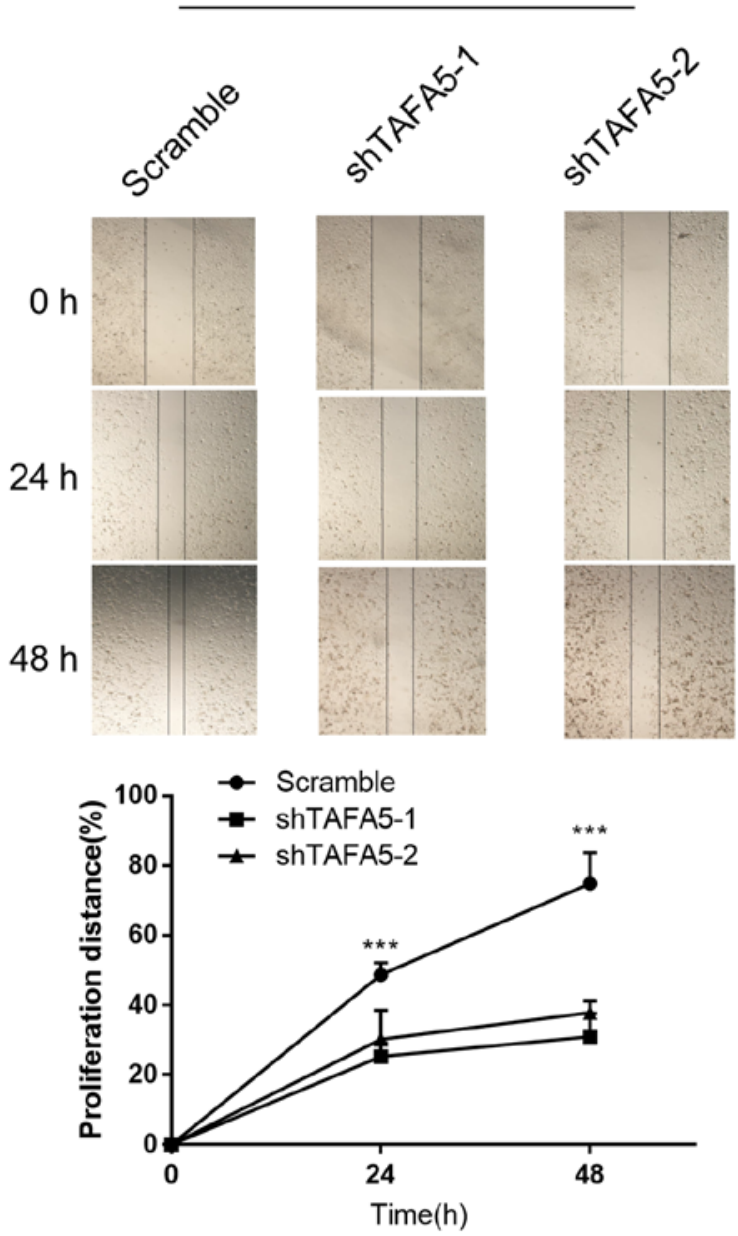

$\mathbf{F}$

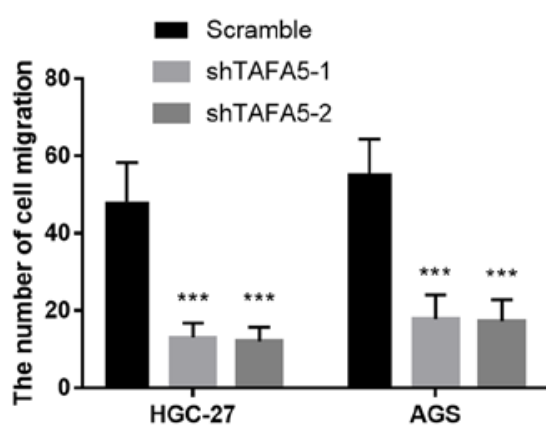

Figure 4. Effect of TAFA5 knockdown in GC cells in vitro. HGC-27 and AGS cells were infected with lentiviruses carrying shTAFA5-1, shTAFA5-2 or scrambled control shRNA. (A and B) Cell proliferation was assayed by Cell Counting Kit-8 assay. (C and D) Scratch wound healing assay (magnification, $\mathrm{x} 100)$. (E and F) Transwell migration assay. Three replicates were conducted for each experiment. ${ }^{* *} \mathrm{P}<0.01,{ }^{* * * *} \mathrm{P}<0.001$ vs. the control group. TAFA5, TAFA chemokine like family member 5 ; GC, gastric cancer; OD, optical density. 
A

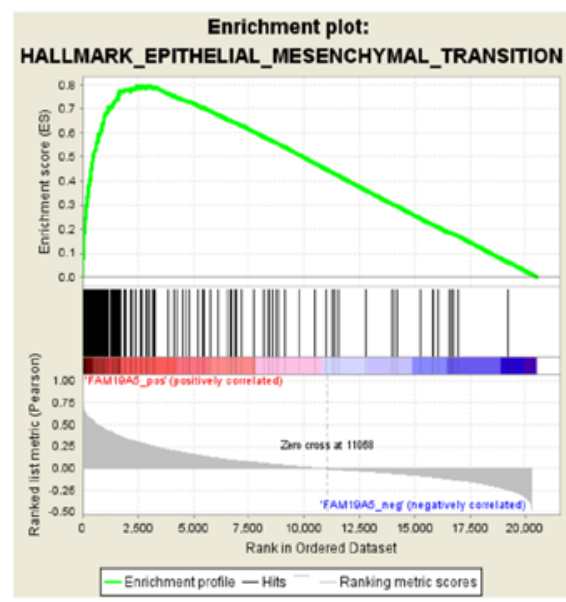

NES=2.16 FDR $q$-value $<0.001$

B
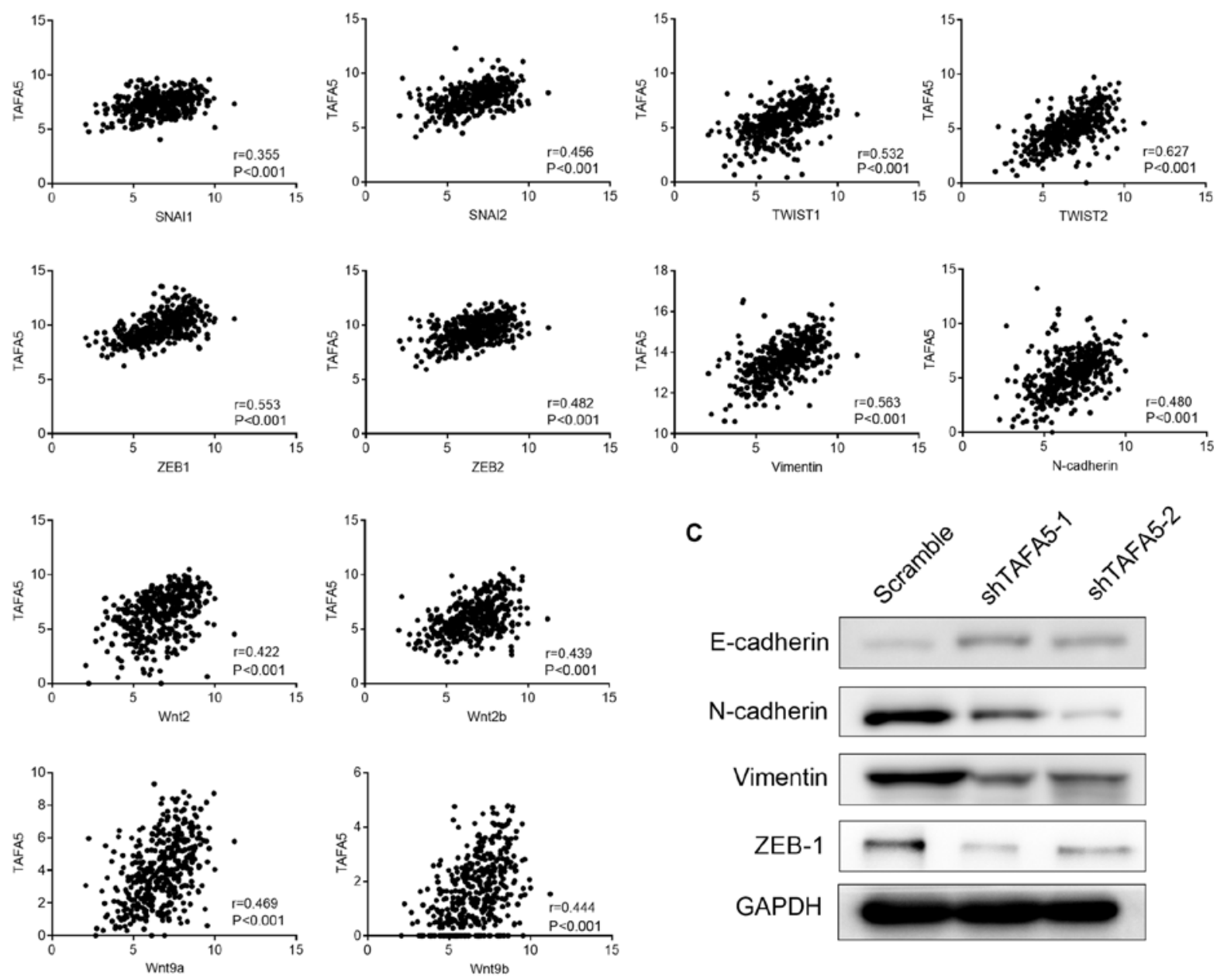

C

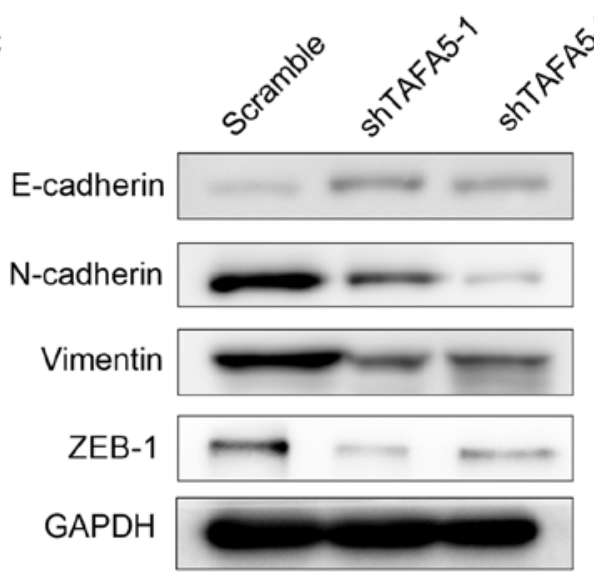

Figure 5. Potential involvement of TAFA5 in the regulation of EMT. (A) GSEA enrichment plots indicated that TAFA5 expression was positively correlated with the EMT gene signature, but not with the Wnt/3-catenin signaling pathway. (B) TAFA5 was moderately correlated with several genes associated with EMT. (C) Western blotting analysis was used to validate the difference in the expressions of epithelial and mesenchymal markers in GC cells infected with shTAFA5 or scramble. GAPDH was used as loading control. TAFA5, TAFA chemokine like family member 5; EMT, epithelial-mesenchymal transition; GSEA, gene set enrichment analysis; GC, gastric cancer; sh, short hairpin RNA; NES, normalized enrichment score; FDR, false discovery rate.

As TAFA family members are mainly expressed in the central nervous system, the majority of studies have focused on the regulation of nerve and hormone homeostasis (24-27). However, TAFA family members encode small secreted proteins that are evolutionarily close to CCL3 (6), whose involvement in various malignancies has been extensively investigated. For example, CCL3 promotes oral carcinogenesis via the induction of inflammatory and angiogenic pathways, and eosinophil 
recruitment (28); it also mediates the cyclophosphamide-induced intratumoral migration of $\mathrm{CD}^{+}{ }^{+} \mathrm{T}$ cells and tumor regression in hepatic carcinomas (29), suggesting a cell type-dependent role in carcinogenesis. Based on these results, these TAFA family members are probably involved in carcinogenesis. In the present study, unfavorable prognostic effects of TAFA5 in patients with GC were reported and the results were validated with two larger patient cohorts. Furthermore, silencing of TAFA5 in GC cells in vitro suppressed cell proliferation and migration. These results indicated that TAFA5 may promote progression of GC.

In total, 5 consensus Lef/Tcf binding sites are located within intron 2 of TAFA5, and at least 2 of these sites have been physically associated with $\beta$-catenin. Thus, TAFA5 is a downstream target of the $\mathrm{Wnt} 9 \mathrm{~b} / \beta$-catenin signaling pathway in the maintenance of nephron progenitor cell renewal $(8,9)$. Furthermore, it has been reported that EMT serves an essential role in tumor progression and is involved in the proliferation and migration of multiple types of human tumors (30). In the present study, GSEA using RNA-seq data from TCGA revealed that TAFA5 expression was positively correlated with genes involved in EMT, but not the Wnt/ $\beta$-catenin signaling pathway. Further correlation analyses using the same data revealed that TAFA5 expression was moderately associated with Wnt9a and Wnt9b, as well as several EMT-activating transcription factors, and only weakly associated with $\beta$-catenin. Based on the complex cross-talk among pathways, these results suggested that TAFA5-induced GC progression may involve multiple pathways. Furthermore, Park et al (10) demonstrated that TAFA5 inhibited osteoclastogenesis via the mediation of its target receptor, formyl peptide receptor 2 (FPR2). In addition, Wang et al (31) revealed that TAFA5 was able to inhibit postinjury neointima formation through sphingosine-1-phosphate receptor 2 (S1PR2). Based on these studies, it is possible that FPR2 and S1PR2 may be potential target receptors that link TAFA5 to the proliferation and migration in GC; this hypothesis warrants further investigation.

There are several limitations in the present study. Firstly, since most cell lines used in the present study were poorly differentiated, it was not possible to determine whether TAFA5 expression is correlated with the aggressiveness of these cell lines. Secondly, as TAFA5 is widespread in serum and has been identified as a novel serum biomarker to differentiate cholangiocarcinoma from benign biliary tract diseases (11), measuring its serum concentration in GC patients may also have clinical significance. As the cases are still accumulating, data from sera analyses were not included in the current study. The above limitations will be addressed in future studies.

In conclusion, the present study identified TAFA5 as a novel prognostic marker for GC, which may accelerate tumor progression by promoting GC cell proliferation and migration via the modulation of EMT-associated pathways. The present results thus highlight the importance of future investigation of this putative marker.

\section{Acknowledgements}

The authors greatly appreciated the technical help from the Department of Pathology of the Fifth People's Hospital of Shanghai for the IHC staining and data analysis. The authors would also like to thank Dr Jun Hou at Zhongshan Hospital
(Shanghai, China) for her interpretation of the IHC staining, as well as Dr Lijie Ma at the Fifth People's Hospital of Shanghai (Shanghai, China) for his work in packaging the lentiviral particles. In addition, the authors give special thanks to Dr Yan Zhang at Carillon Clinic (Roanoke, VA, USA) for his valuable work on data mining and the processing of TCGA RNA-seq dataset.

\section{Funding}

The present study was supported by the Institutional Grants for Newly Imported Talents of the Fifth People's Hospital of Shanghai, Fudan University (grant no. 2016WYRC01), the Talent Program of the Fifth People's Hospital of Shanghai, Fudan University (grant no. 2017WYRCSG 01), the Great Discipline Construction Project from the Medical System Shanghai Minhang District (grant no. 2017MWDXK01), the Research Grant from Shanghai Minhang District Health and Family Planning Commission (grant no. 2016MW03), and the Research Grant from Shanghai Minhang District Science and Technology Commission (grant no. 2017MHZ02).

\section{Availability of data and materials}

The datasets used and/or analyzed during the current study are available from the corresponding author on reasonable request.

\section{Authors' contributions}

CK designed the study. ZH, GN, JR, XW, LC and RH performed the experiments. $\mathrm{ZH}$ and GN wrote the manuscript. $\mathrm{CK}$ and JR revised the manuscript for important intellectual content. All authors read and approved the final manuscript.

\section{Ethics approval and consent to participate}

The present study was approved by the Institutional Ethics Committee at the Fifth People's Hospital of Shanghai, Fudan University (ethical approval no. 2017-097) and adhered to the principles in the Declaration of Helsinki. Written informed consent was obtained from each patient prior to tissue collection for experimentation.

\section{Patient consent for publication}

Not applicable.

\section{Competing interests}

The authors declare that they have no competing interests.

\section{References}

1. Torre LA, Bray F, Siegel RL, Ferlay J, Lortet-Tieulent J and Jemal A: Global cancer statistics, 2012. CA Cancer J Clin 65: 87-108, 2015.

2. Siegel RL, Miller KD and Jemal A: Cancer statistics, 2018. CA Cancer J Clin 68: 7-30, 2018.

3. Malvezzi M, Bonifazi M, Bertuccio P, Levi F, La Vecchia C, Decarli A and Negri E: An age-period-cohort analysis of gastric cancer mortality from 1950 to 2007 in Europe. Ann Epidemol 20: 898-905, 2010. 
4. Chen W, Zheng R, Baade PD, Zhang S, Zeng H, Bray F, Jemal A Yu XQ and He J: Cancer statistics in China, 2015. CA Cancer J Clin 66: 115-132, 2016.

5. Van Cutsem E, Sagaert X, Topal B, Haustermans K and Prenen H: Gastric cancer. Lancet 388: 2654-2664, 2016.

6. Tom Tang Y, Emtage P, Funk WD, Hu T, Arterburn M, Park EE and Rupp F: TAFA: A novel secreted family with conserved cysteine residues and restricted expression in the brain. Genomics 83: 727-734, 2004.

7. Paulsen SJ, Christensen MT, Vrang N and Larsen LK: The putative neuropeptide TAFA5 is expressed in the hypothalamic paraventricular nucleus and is regulated by dehydration. Brain Res 1199: 1-9, 2008.

8. Pan X, Karner CM and Carroll TJ: Myc cooperates with beta-catenin to drive gene expression in nephron progenitor cells. Development 144: 4173-4182, 2017.

9. Karner CM, Das A, Ma Z, Self M, Chen C, Lum L, Oliver G and Carroll TJ: Canonical Wnt9b signaling balances progenitor cell expansion and differentiation during kidney development. Development 138: 1247-1257, 2011.

10. Park MY, Kim HS, Lee M, Park B, Lee HY, Cho EB, Seong JY and Bae YS: FAM19A5, a brain-specific chemokine, inhibits RANKL-induced osteoclast formation through formyl peptide receptor 2. Sci Rep 7: 15575, 2017.

11. Janvilisri T, Leelawat K, Roytrakul S, Paemanee A and Tohtong R: Novel serum biomarkers to differentiate cholangiocarcinoma from benign biliary tract diseases using a proteomic approach. Dis Markers 2015: 105358, 2015.

12. Diaz de Stahl T, Hartmann C, de Bustos C, Piotrowski A, Benetkiewicz M, Mantripragada KK, Tykwinski T, von Deimling A and Dumanski JP: Chromosome 22 tiling-path array-CGH analysis identifies germ-line- and tumor-specific aberrations in patients with glioblastoma multiforme. Genes Chromosomes Cancer 44: 161-169, 2005.

13. Wu C, Miao X, Huang L, Che X, Jiang G, Yu D, Yang X, Cao G Hu Z, Zhou Y, et al: Genome-wide association study identifies five loci associated with susceptibility to pancreatic cancer in Chinese populations. Nat Genet 44: 62-66, 2011.

14. Howitt BE, Sun HH, Roemer MG, Kelley A, Chapuy B, Aviki E, Pak C, Connelly C, Gjini E, Shi Y, et al: Genetic basis for PD-L1 expression in squamous cell carcinomas of the cervix and vulva. JAMA Oncol 2: 518-522, 2016.

15. Shi JY, Ma LJ, Zhang JW, Duan M, Ding ZB, Yang LX, Cao Y, Zhou J, Fan J, Zhang X, et al: FOXP3 is a HCC suppressor gene and Acts through regulating the TGF-beta/Smad2/3 signaling pathway. BMC Cancer 17: 648, 2017.

16. Livak KJ and Schmittgen TD: Analysis of relative gene expression data using real-time quantitative PCR and the 2(-Delta Delta C(T)) method. Methods 25: 402-408, 2001.

17. Zhao S, Zhou L, Niu G, Li Y, Zhao D and Zeng H: Differential regulation of orphan nuclear receptor TR3 transcript variants by novel vascular growth factor signaling pathways. FASEB J 28 : 4524-4533, 2014

18. Hu HM, Chen Y, Liu L, Zhang CG, Wang W, Gong K, Huang Z, Guo MX, Li WX and Li W: Clorf61 acts as a tumor activator in human hepatocellular carcinoma and is associated with tumorigenesis and metastasis. Faseb J 27: 163-173, 2013.

19. Niu G, Ye T, Qin L, Bourbon PM, Chang C, Zhao S, Li Y, Zhou L, Cui P, Rabinovitz I, et al: Orphan nuclear receptor TR3/Nur77 improves wound healing by upregulating the expression of integrin $\beta 4$. Faseb J 29: 131-140, 2015.
20. D'Errico M, de Rinaldis E, Blasi MF, Viti V, Falchetti M, Calcagnile A, Sera F, Saieva C, Ottini L, Palli D, et al: Genomewide expression profile of sporadic gastric cancers with microsatellite instability. Eur J Cancer 45: 461-469, 2009.

21. Cho JY, Lim JY, Cheong JH, Park YY, Yoon SL, Kim SM, Kim SB, Kim H, Hong SW, Park YN et al: Gene expression signature-based prognostic risk score in gastric cancer. Clin Cancer Res 17: 1850-1857, 2011.

22. Subramanian A, Tamayo P, Mootha VK, Mukherjee S, Ebert BL, Gillette MA, Paulovich A, Pomeroy SL, Golub TR, Lander ES and Mesirov JP: Gene set enrichment analysis: A knowledge-based approach for interpreting genome-wide expression profiles. Proc Natl Acad Sci USA 102: 15545-15550, 2005.

23. Mootha VK, Lindgren CM, Eriksson KF, Subramanian A, Sihag S, Lehar J, Puigserver P, Carlsson E, Ridderstråle M, Laurila E, et al: PGC-1alpha-responsive genes involved in oxidative phosphorylation are coordinately downregulated in human diabetes. Nat Genet 34: 267, 2003.

24. Zheng C, Chen D, Zhang Y, Bai Y, Huang S, Zheng D, Liang W, She S, Peng X, Wang P, et al: FAM19A1 is a new ligand for GPR1 that modulates neural stem-cell proliferation and Differentiation. Faseb J fj201800020RRR, 2018.

25. Wang X, Shen C, Chen X, Wang J, Cui X, Wang Y, Zhang H, Tang L, Lu S, Fei J and Wang Z: Tafa-2 plays an essential role in neuronal survival and neurobiological function in mice. Acta Biochim Biophys Sin (Shanghai) 50: 984-995, 2018

26. Kambrun C, Roca-Lapirot O, Salio C, Landry M, Moqrich A and Le Feuvre Y: TAFA4 Reverses Mechanical Allodynia through Activation of GABAergic Transmission and Microglial Process Retraction. Cell Rep 22: 2886-2897, 2018.

27. Shao Y, Deng T, Zhang T, Li P and Wang Y: FAM19A3, a novel secreted protein, modulates the microglia/macrophage polarization dynamics and ameliorates cerebral ischemia. FEBS Lett 589: 467-475, 2015.

28. da Silva JM, Moreira Dos Santos TP, Sobral LM, QueirozJunior CM, Rachid MA, Proudfoot AEI, Garlet GP, Batista AC, Teixeira MM, Leopoldino AM, et al: Relevance of CCL3/CCR5 axis in oral carcinogenesis. Oncotarget 8: 51024-51036, 2017.

29. Naito T, Baba T, Takeda K, Sasaki S, Nakamoto Y and Mukaida N: High-dose cyclophosphamide induces specific tumor immunity with concomitant recruitment of LAMP1/CD107a-expressing CD4-positive T cells into tumor sites. Cancer Lett 366: 93-99, 2015.

30. De Craene B and Berx G: Regulatory networks defining EMT during cancer initiation and progression. Nat Rev Cancer 13: 97-110, 2013

31. Wang Y, Chen D, Zhang Y, Wang P, Zheng C, Zhang S, Yu B, Zhang L, Zhao G, Ma B, et al: Novel Adipokine, FAM19A5, inhibits neointima formation after injury through sphingosine-1-phosphate receptor 2. Circulation 138: 48-63, 2018.

This work is licensed under a Creative Commons Attribution-NonCommercial-NoDerivatives 4.0 International (CC BY-NC-ND 4.0) License. 